\title{
NEM SÓ COM ROYALTIES SE MELHORA QUALIDADE DA EDUCAÇÃO
}

Coluna publicada em 30.7.2013: <http://www.conjur.com.br/2013-jul-30/ contas-vista-nem-royalties-melhora-qualidade-educacao $>$

Nas últimas semanas a mídia tornou a trazer para o centro do debate a sempre presente questão dos gastos com educação. A destinação de percentual do PIB, bem como dos royalties de petróleo para a educação, associada às manifestações recentes, em que se observou uma quase unanimidade nas reivindicações pela melhoria no sistema, é um dos assuntos recentes que fizeram o tema voltar à discussão. Uma excelente oportunidade para tratar do tema sob o prisma do Direito Financeiro.

A educação é indiscutivelmente uma prioridade, não só do Brasil como de qualquer país do mundo que seja ou pretenda ser considerado desenvolvido. Não se vislumbra possível atingir os objetivos fundamentais fixados em nossa Constituição (art. $3^{\circ}$ ), construindo uma sociedade livre, justa e solidária, garantindo o desenvolvimento nacional, com erradicação da pobreza e desigualdades, promovendo o bem de todos, sem uma educação universalizada e de qualidade.

Investir na educação, alocando os recursos públicos maciçamente neste setor é verdadeiramente uma obrigação de todo e qualquer administrador público, não há dúvida. O que importa destacar é como fazer isso. A educação, no Brasil, e as respectivas políticas públicas voltadas ao setor compõem um sistema complexo e que precisa ser muito bem estruturado, organizado e gerido.

Somos uma República Federativa presidencialista, com três esferas de governo bem definidas e três poderes independentes, mais as várias instituições dotadas de autonomia administrativa e financeira, o que torna mais complexa e delicada a tarefa de estruturar um sistema de forma organizada e eficiente para alcançar suas finalidades.

A educação, tema caro ao nosso legislador constituinte, que dele tratou longamente em nosso texto constitucional, com uma seção inteiramente dedicada a esse setor (Capítulo III, Seção I, arts. 205 a 214, sem contar outros dispositivos ao longo 
do texto), previu ser a educação um direito de todos e dever do Estado e da família, assegurando-se pleno acesso a todos, com gratuidade do ensino público e garantia de padrão de qualidade, entre outros princípios.

Tudo isso a ser executado pelas três esferas de governo, ficando a cargo da União, Estados, Distrito Federal e Municípios, em regime de colaboração (CF, art. 211), sem prejuízo da participação da iniciativa privada (CF, art. 209). E com compartilhamento de recursos entre todos, especialmente por meio do Fundeb (Fundo de Manutenção e Desenvolvimento da Educação Básica e de Valorização dos Profissionais da Educação - CF, ADCT, art. 60), em uma clara política pública a ser realizada no âmbito de nosso sistema de federalismo cooperativo, que caracteriza nosso Estado.

Gerir todo esse sistema de modo a fazer com que todos caminhem no mesmo sentido e se voltem a um objetivo único, que é aplicar bem os recursos para melhorar esse serviço público fundamental para o desenvolvimento econômico e social do país, não é, a toda evidência, tarefa simples.

Requer, primeiramente, um planejamento bem elaborado e eficiente, o que, no caso da educação, já conta com um tratamento diferenciado, na medida em que a Constituição prevê lei de caráter nacional estabelecendo o Plano Nacional de Educação (PNE) para o período de dez anos. Trata-se de um instrumento da maior relevância para a gestão desse sistema, pois define, para todos os entes da federação, diretrizes, objetivos, metas e estratégias para o setor, bem como os meios a serem utilizados para alcançá-los (CF, art. 214).

O primeiro PNE surgiu com a Lei 10.172/2001, para o período 2001-2010, estabelecendo as principais regras para o setor a serem seguidas por todos os entes da federação, determinando aos entes subnacionais que elaborem seus respectivos planos decenais (art. $2^{\circ}$ ), exigindo que os planos plurianuais de todos os entes federados sejam elaborados de modo a dar suporte às metas estabelecidas (art. $5^{\circ}$ ) e que todos os poderes se empenhem para a realização dos objetivos e metas dos planos (art. $6^{\circ}$ ).

Vê-se que o prazo do referido plano já expirou e, não obstante tenha sido apresentado o projeto de lei para sucedê-lo no período 2011-2020, este permanece em discussão no Congresso Nacional, que está falhando gravemente ao não lograr aprová-lo, fazendo com que já entremos no terceiro ano de verdadeira "anomia legislativa” nessa área fundamental, e em período no qual a população clama por mais educação e com qualidade.

O prejuízo é enorme para todos, pois causa insegurança e desordem no sistema jurídico. Veja-se que o PPA (plano plurianual) da União, que planeja a administração pública federal, elaborado para o período 2012-2015, bem como os dos estados e Distrito Federal, também elaborados para o mesmo período, foram feitos com base no projeto de lei do PNE ainda não aprovado. E não será diferente com 
os municípios, que deverão, no segundo semestre deste ano, fazer o mesmo, apresentando suas propostas de PPA para o período 2014-2017 sem que tenha sido aprovado o PNE no qual devem se basear. Mais do que insegurança jurídica, causa desordem na administração pública e respectivos orçamentos e contabilidade pública, gerando ineficiência geral, com prejuízos ao andamento de projetos, contratações e licitações.

Neste ponto cabe uma ponderação importante. Repetindo o que já escrevi (Responsabilidade orçamentária precisa de melhorias, nesta edição, p. 259-262), ressalto que devem as preocupações se concentrar mais na qualidade do gasto do que na quantidade, o que não parece estar ocorrendo.

Em todos os fatos mencionados no início desta coluna, o que se vê é um foco em procurar o aumento dos recursos para a educação, pelas mais diversas vias criando uma obrigação de gastar $10 \%$ dos recursos públicos em proporção do PIB com a educação e a pretensão de alocar $100 \%$ das receitas arrecadadas com royalties de petróleo no setor. São todas medidas, que, com a melhor das intençôes, se imaginam suficientes para resolver o problema. E, por mais estranho que possa ser, comprovadamente não são.

O maior problema da administração pública, por mais curioso que possa parecer, não é a quantidade de recursos, mas sim conseguir administrá-los de forma eficiente. $\mathrm{Na}$ educação a situação não é diferente. Também já falei sobre isso, há exatamente um ano, e nunca é demais voltar ao tema (Não falta dinheiro à administração pública, falta gestão, nesta edição, p. 255-258). As recentes notícias mencionadas no início desta coluna apontam claramente neste sentido: "As principais falhas na área educacional no Brasil, segundo pesquisadores, estão relacionadas à má distribuição e à gestão ineficiente dos recursos"; ${ }^{1}$ dados de recente levantamento da $\mathrm{OCDE},{ }^{2}$ mostrando que o aumento nos gastos com educação que o Brasil fez nos últimos anos não está resultando em efetiva melhoria em nossos índices, "deveriam ser lidos com muita atenção por governantes e pelos manifestantes que foram às ruas clamar por uma educação melhor, sob pena de insistirmos na tecla errada: aumentar o volume de gastos no setor não deve trazer a qualidade educacional de que precisamos". ${ }^{3}$ Mailson da Nóbrega, em recente coluna publicada, é claro e preciso ao afirmar que o problema da educação não é a falta de dinheiro, pois o que a educação brasileira precisa é "de uma verdadeira revolução gerencial e

Aprendendo a gastar. Folha de S.Paulo, 30 de junho de 2013, p. B8.

2 Education at a glance 2013.

3 Dados novos, problema antigo. Revista Veja, ed. 2.330, 10 de julho de 2013, p. 100. 
de prioridades, inclusive para gastar melhor os recursos disponíveis", ${ }_{4}^{4}$ no mesmo sentido do apelo de Gustavo Ioschpe. 5

Maior prova disso é ver que a preocupação com a quantidade de recursos para a educação é antiga, já vem pelo menos desde a promulgação da Constituição, que em seu texto original, publicado em 1988, prevê que a União deverá aplicar anualmente, no mínimo, $18 \%$ da receita de impostos e transferências obrigatórias na manutenção e desenvolvimento do ensino, e estados, Distrito Federal e municípios, o mínimo de $25 \%$, destacando-se ainda entes da federação que, por legislação própria, preveem valores ainda mais altos, como é o caso do estado de São Paulo, cujo percentual é de 30\% (CF, art. 255), e do município de São Paulo, com percentual de 31\% (Lei Orgânica, art. 208).

E não se pode dizer que, após todos esses anos, a questão da educação, que sem dúvida experimentou avanços nesse período, esteja próxima do ideal almejado pela nossa sociedade, que tem se mostrado atenta a esta questão, como se vê nas ruas.

Não será somente pela obrigação de elevar a meta de aplicação de recursos públicos em educação em proporção do PIB, como determina a Constituição (art. 214, VI) e debate-se no projeto do novo - e já atrasado - Plano Nacional de Educação, nem pela destinação dos recursos dos royalties de petróleo do pré-sal, que a questão será resolvida.

A sociedade, por todos os seus órgãos representativos, faz muito bem e realiza o excelente trabalho nesta luta pelos recursos para a educação. Certamente isso poderá resultar, ao menos, em aumento de salário aos professores, que precisam e merecem. Poucas causas podem ser mais nobres do que essa, e essa deve ser uma luta incessante de todos.

Todo o apoio deve ser dado aos parlamentares e membros do Poder Executivo no sentido de conseguirem aprovar mais recursos para a educação, mas já passou da hora de canalizarem suas energias para aperfeiçoar a gestão dos recursos que já estão sendo aplicados, sob pena de mandar mais dinheiro para um sistema que ainda não está conseguindo administrar bem o que já tem. E isso pode começar com a aprovação do Plano Nacional de Educação. ${ }^{6}$

4 O problema da educação não é a falta de dinheiro. Revista Veja, ed. 2.331, 24 de julho de 2013, p. 32.

5 Dilma, não desperdice nossos recursos nesse sistema educacional. Revista Veja, ed. 2.331, 24 de julho de 2013, p. 104.

6 O Plano Nacional de Educação foi aprovado em 25 de junho de 2014 (Lei 13.005). 